\title{
A inclusão de Pessoas COM NECESSIDAdES ESPECIAIS NO TRABALHO: A VISÃO DE EMPRESAS E DE INSTITUIÇÕES EDUCACIONAIS ESPECIAIS NA CIDADE DE Curitiba
}

INCLUSION OF PEOPLE WITH SPECIAL NEEDS AT WORK: THE POINT OF VIEW OF BUSINESSES AND SPECIAL NEEDS EDUCATIONAL INSTITUTIONS IN CURITIBA

\author{
Janine Plaça ARAUJO ${ }^{1}$ \\ Andréia SCHMIDT ${ }^{2}$
}

\begin{abstract}
RESUMO: a inclusão é um processo pelo qual a sociedade se adapta para permitir a participação das pessoas em todos os seus setores, inclusive daquelas pessoas com necessidades especiais (PNE's), e estas, por sua vez, se preparam para assumir seus papéis na sociedade. O acesso de PNE's ao mercado de trabalho é um dos aspectos do processo de inclusão, importante por proporcionar às pessoas condições para a satisfação de suas necessidades básicas, a valorização de si mesmas e o desenvolvimento de suas potencialidades. O objetivo dessa pesquisa foi levantar, junto a empresas com mais de 100 funcionários e a instituições que atendem jovens e adultos com necessidades especiais, quais as práticas que vêm sendo adotadas para inclusão de PNE's no mercado de trabalho e as eventuais dificuldades encontradas nesse processo. Foram realizadas entrevistas com 30 empresas e 10 instituições educacionais, todas na cidade de Curitiba (PR). Os resultados indicaram que as empresas não cumprem a Lei de Cotas, que regulamenta a contratação de PNE's. As empresas afirmam que o maior empecilho para isso é a baixa escolarização das PNE's e sua baixa qualificação profissional. As instituições educacionais criticam os processos adotados pelas empresas na contratação de PNE's, mas poucas oferecem escolarização para seus alunos, concentrando-se, em sua maioria, no desenvolvimento de habilidades básicas para o trabalho ou em capacitação profissional eventualmente diferente daquela exigida pelo mercado de trabalho. São discutidas, também, as contradições encontradas entre legislação, práticas educacionais e mercado de trabalho, no que diz respeito à inclusão.
\end{abstract}

PALAVRAS-CHAVE: inclusão no mercado de trabalho; pessoa com necessidades especiais; empresas; instituições de educação especial.

ABSTRACT: inclusion is a process whereby society adapts so as to allow full participation to people from all sectors, including people with special needs (PSN), as they prepare to become regular members of society. PSN's access to the job market is among the aspects of the process of inclusion, whose importance relates to the promotion of conditions for satisfying their basic needs, achieving self worth and developing their full potential. The aim in this research was to investigate businesses with more than 100 employees and institutions that work with young people and adults with special needs, so as to identify what they are doing to promote inclusion of PSNs in the job market and uncover possible difficulties they have faced during the process. We interviewed professionals in 30 businesses and 10 educational institutions, all located in Curitiba, the capital of the southern State of Paraná (PR). The results showed that most businesses do not obey the national Quota Law which establishes the minimum quota for hiring PSNs. According to the businesses consulted, the main problem lies in the PSNs low level of education and their lack of professional qualifications. The educational institutions criticize the processes adopted by some of the companies hiring PSNs, however few of these institutions offer proper schooling for their students, concentrating instead, for the most part, on developing basic work habits or investing in developing work related skills in areas other than those required by the job market. Also discussed in this paper are some of the contradictions found in our legislation, educational practice and job market, as related to inclusion.

KEYWORDS: inclusion in the job market; people with special needs; business; special education institutions.

\footnotetext{
${ }^{1}$ Aluna de Psicologia do Centro Universitário Positivo. Curitiva - PR. - jaraujo@positivo.com.br

${ }^{2}$ Doutora em Psicologia e professora do do Centro Universitário Positivo, Curitiba - PR -

andreia.schmidt@unicenp.edu.br
} 


\section{INTRODUÇão}

De acordo com o Censo de 2000, 14,4\% da população brasileira tem necessidades especiais. Esse percentual corresponde a aproximadamente 24,5 milhões de pessoas, cuja média de empregabilidade é de apenas 2,05\% (NERI; CARVALHO; COSTILHA, 2002). Esse dado aponta para duas questões importantes a serem discutidas. A primeira delas diz respeito à existência e à viabilidade de mecanismos sociais e governamentais que garantam acesso ao emprego às pessoas com necessidades especiais (PNE's). A segunda delas é a análise das ações concretas levadas a cabo pela sociedade para efetivar o processo de inclusão de PNE's no mercado de trabalho.

A necessidade de se criar mecanismos de acesso da PNE ao mercado de trabalho faz parte de um processo mais amplo de inclusão social dessas pessoas. De acordo com Martins (2003), as PNE's representam uma minoria na sociedade, o que favoreceu a sua marginalização e exclusão ao longo dos tempos, inclusive do acesso à educação, o que ocasionou, de forma mais ampla, a privação dessas pessoas de uma série de bens culturais e intelectuais, prejudicando-as no seu processo de inserção social e trabalhista. A idéia de inclusão se fundamenta no princípio do reconhecimento da diversidade na vida em sociedade, o que garantiria o acesso de todos os indivíduos às oportunidades, independente de suas peculiaridades (ARANHA, 2001). Nesse sentido, a inclusão se constitui em um processo bilateral, no qual as pessoas excluídas e a sociedade buscam, em parceria, equacionar problemas, tomar decisões para sua solução e tornar realidade a equiparação de oportunidades para todos (SASSAKI, 1997).

No âmbito trabalhista o Brasil possui uma legislação bastante ampla que garante às PNE's o acesso ao mercado de trabalho. A Constituição Brasileira de 1988 e a Lei 8.213 de 24 de julho de 1991 são os principais documentos que asseguram às PNE's o direito de acesso ao mercado de trabalho (público e privado). A Constituição Federal veta a discriminação no tocante a salários e critérios de admissão para os trabalhadores com qualquer tipo de deficiência (art. 7, XXXI) e instituiu a reserva de $20 \%$ de cargos e empregos públicos para PNE's (art. 37, VIII). Já a Lei 8.213/91 (art. 93), a chamada Lei de Cotas, estabeleceu que todas as empresas privadas com mais de 100 funcionários devem preencher entre 2 e $5 \%$ de suas vagas com trabalhadores que tenham algum tipo de necessidade especial. Esse percentual varia em função do número de funcionários da instituição: empresas com até 200 funcionários devem ter $2 \%$ de suas vagas preenchidas por PNE's; entre 201 e 500 funcionários, 3\%; entre 501 e 1000 funcionários, 4\%; empresas com mais de 1001 funcionários, $5 \%$ das vagas.

Apesar da legislação admitir preferência para PNE's na ocupação de um percentual variável de vagas no serviço público e privado, o princípio norteador dessas ações afirmativas é a tentativa de assegurar a igualdade de oportunidade de acesso ao mercado de trabalho a essas pessoas, e não apenas impor procedimentos assistencialistas às empresas. Isso quer dizer que as PNE's precisam 
ter qualificação e aptidão física para ocupar as vagas a elas destinadas, o que remete ao segundo ponto de discussão desse trabalho.

Um dos maiores problemas detectados no início do século XXI é o desemprego e a conseqüente exclusão social (DILL, 2001). Um dos motivos para isso parece ser a globalização dos mercados, que exige das empresas um grau maior de produtividade a baixos custos. Tais exigências, para serem cumpridas, requerem trabalhadores cada vez mais capacitados profissionalmente, tanto no que se refere à escolarização quanto à especialização para o desempenho de funções técnicas. Países em desenvolvimento como o Brasil ainda apresentam muitos problemas para universalizar a oferta de condições de preparo para sua população (educação, saúde, assistência social, etc.), o que dificulta ainda mais o acesso de uma parcela significativa da população ao mercado de trabalho, promovendo a exclusão não apenas das pessoas com necessidades especiais.

O preparo de PNE's para o mercado de trabalho demanda a construção de programas específicos que tenham como principal objetivo a adoção de práticas que possibilitem a entrada dessas pessoas no mercado de trabalho de forma competitiva (TANAKA; RODRIGUES, 2003). Tais programas devem levar em conta não apenas as peculiaridades das necessidades especiais dos indivíduos, mas seu potencial de realização.

A história de oferta de profissionalização para PNE's passou por diversas fases ao longo dos tempos. De acordo com SASSAKI (1997), pode-se identificar diferentes momentos nos procedimentos de profissionalização adotados pela sociedade e direcionadas às PNE's. Na fase da exclusão, o acesso ao mercado de trabalho para as PNE's era negado, pois o trabalho dessas pessoas era tido como uma forma de exploração. A exclusão também se dava (e ainda se dá) em função da crença de que as necessidades especiais são um impeditivo para o trabalho, o que denota desconhecimento e desconsideração das potencialidades das PNE's. Na fase considerada de segregação, as instituições educacionais filantrópicas passaram a estabelecer parcerias com empresas privadas e as PNE's passaram a executar trabalhos no interior das instituições (oficinas protegidas) ou no próprio domicílio. A justificativa para tais ações era de que haveria um benefício comum a todos os participantes do processo: o aluno se beneficiaria com a obtenção de uma renda, da mesma forma que a instituição, e a empresa obteria trabalho de qualidade com boa lucratividade. Tais argumentos são contestáveis. O trabalho do PNE não pode ser concebido como uma saída para os problemas econômicos das escolas especializadas em dar formação profissional a essa clientela. Além disso, o atendimento profissionalizante era algo imposto à PNE e poderia não corresponder às suas necessidades. Do ponto de vista das empresas empregadoras, a prática do trabalho segregado denotava a natureza da relação empregador-empregado: a PNE seria boa empregada para o empregador que busca o lucro, "pois, por ser considerado deficiente, seu trabalho passa a valer menos ainda que o dos demais, independentemente de sua qualidade" (GOYOS; MANZINI; CARVALHO; BALTHAZAR; MIRANDA, 1989, p.58). 
$\mathrm{Na}$ fase de integração, diversas modalidades de trabalho eram oferecidas às PNE's: o trabalho plenamente integrado, no qual PNE's trabalhavam em setores de empresas públicas ou privadas sem que houvesse qualquer reestruturação ambiental ou cultural da própria empresa para receber tais funcionários; trabalho integrado, no qual as empresas se dispunham a fazer pequenas alterações em seu espaço físico ou nos postos de trabalho para favorecer a colocação de PNE's; e trabalho semi-integrado, em que as PNE's trabalhavam em setores exclusivos das empresas, portanto segregativos, com ou sem alterações (AMARAL, 1993³ , citada por SASSAKI, 1997). Essas formas de integração favorecem que os funcionários com necessidades especiais tenham dificuldade em se envolver em programas de treinamento e desenvolvimento de recursos humanos, seja por dificuldades de acesso, seja por falta de integração social real com os demais participantes da empresa.

Na fase da inclusão, o que se pretende é que empregadores, instituições formadoras e PNE's enfrentem juntos os desafios da qualificação, da produtividade e da competitividade. No Brasil, a profissionalização de PNE's tem sido oferecida, prioritariamente, por instituições especializadas, por centros de reabilitação e por associações de pessoas deficientes. As modalidades de profissionalização oferecidas vão desde o treinamento para a colocação em emprego competitivo até o programa de emprego apoiado, passando por alternativas como o trabalho protegido (oficinas) ou programas de pré-profissionalização (SASSAKI, 1997). A literatura atual tem se mostrado favorável a programas de emprego apoiado como forma viável de inclusão de PNE's no mercado de trabalho, apesar dessa ainda ser uma modalidade pouco difundida entre as agências profissionalizantes (RAGAZZI, 2001; ARANHA, 2003).

Como se pode observar a partir desse panorama, existe no Brasil um conjunto de leis que assegura o direto de acesso das PNE's ao mercado de trabalho e uma construção histórica de práticas de profissionalização e inserção no trabalho, além de estudos que apontam caminhos possíveis para a melhoria do processo. A existência desses instrumentos legais e conhecimentos, porém, não garante que a inclusão esteja, de fato, ocorrendo. A implementação de programas de formação e o cumprimento de políticas de ação afirmativa esbarram em dificuldades de ordem prática que nem sempre são identificadas ou estudadas a tempo pelos agentes envolvidos. Em razão disso, o objetivo dessa pesquisa foi levantar junto a empresas com mais de 100 funcionários e a instituições que atendem jovens e adultos com necessidades especiais na cidade de Curitiba, quais práticas vêm sendo adotadas para inclusão de PNE's no mercado de trabalho e as eventuais dificuldades encontradas nesse processo.

\footnotetext{
${ }^{3}$ AMARAL, L.A. Falando sobre o trabalho da pessoa portadora de deficiência. In: A questão do trabalho e a pessoa portadora de deficiência. São Paulo: REINTEGRA, 1993. 22p. apost.
} 


\section{Método}

\section{Participantes}

Participaram dessa pesquisa 30 empresas do setor privado de diferentes ramos de atividade, todas com mais de 100 funcionários. Inicialmente, foi feito contato com 57 empresas, escolhidas aleatoriamente pela lista telefônica, mas apenas 30 aceitaram responder à entrevista proposta. Também participaram da pesquisa 10 instituições educacionais que atendem adolescentes e adultos com necessidades especiais. Todas as empresas e instituições participantes estão localizadas na cidade de Curitiba (PR).

\section{INSTRUMENTOS}

Foram empregados dois roteiros de entrevista na pesquisa. O primeiro, aplicado às empresas, continha 10 perguntas que faziam a caracterização da empresa e abordavam o processo de contratação de pessoas com necessidades especiais. O segundo roteiro, destinado às instituições educacionais, era composto por 13 perguntas que investigavam o processo profissionalização e colocação no mercado de trabalho oferecido pela instituição.

\section{Procedimentos}

Após aprovação da pesquisa pelo Comitê de Ética em Pesquisa do Centro Universitário Positivo, todos os participantes (empresas e instituições educacionais) foram contatados via telefone. Nesse primeiro contato foram explicados os objetivos da pesquisa e a forma como as informações coletadas seriam empregadas. As entrevistas foram realizadas pessoalmente nas dependências das empresas e instituições que aceitaram participar da pesquisa. Todas as empresas e instituições assinaram um termo de consentimento livre e esclarecido para participar da pesquisa. Um terceiro e último contato foi estabelecido com os participantes, via e-mail, para envio dos resultados gerais do trabalho.

\section{Resultados}

\section{CARACTERIZAÇÃo DAS EMPRESAS}

As 30 empresas participantes da pesquisa pertenciam a diversos ramos de atividades e possuíam em seu quadro funcional entre 111 e 23.000 funcionários. A maioria das empresas (57\%) pertencia ao ramo industrial, enquanto que $30 \%$ delas eram prestadoras de serviço e $13 \%$ eram empresas comerciais. Pode-se observar na Tabela 1 que apenas quatro empresas (13\% da amostra) cumpriam a Lei de Cotas para contratação de pessoas com necessidades especiais. Também é possível observar que, quanto maior o número de funcionários na empresa, maior o número de vagas não preenchidas por pessoas com necessidades especiais. $\mathrm{Na}$ maioria das empresas ( $56 \%$ delas) os cargos ocupados por PNE's eram operacionais. 
Tabela 1 - caracterização geral das empresas participantes.

\begin{tabular}{|c|c|c|c|c|}
\hline $\begin{array}{l}\text { Ramo de atividade da } \\
\text { empresa }\end{array}$ & $\begin{array}{l}\mathrm{N}^{\circ} \mathrm{de} \\
\text { funcionários }\end{array}$ & $\begin{array}{l}\mathrm{N}^{\circ} \text { de PNE's } \\
\text { contratadas }\end{array}$ & $\begin{array}{l}\mathrm{N}^{\circ} \text { de } \\
\text { contratações } \\
\text { exigidas pela } \\
\text { Lei de Cotas }\end{array}$ & $\begin{array}{l}\text { Relação entre } \\
\text { as contratações } \\
\text { efetivadas e as } \\
\text { exigidas }\end{array}$ \\
\hline Comércio & 111 & 0 & 2 & -2 \\
\hline Indústria & 126 & 0 & 3 & -3 \\
\hline Prestação de serviços & 150 & 2 & 3 & -1 \\
\hline Indústria & 170 & 1 & 3 & -2 \\
\hline Indústria & 216 & 2 & 6 & -4 \\
\hline Indústria & 230 & 6 & 7 & -1 \\
\hline Indústria & 250 & 3 & 8 & -5 \\
\hline Comércio & 270 & 6 & 5 & 1 \\
\hline Comércio & 300 & 6 & 9 & -3 \\
\hline Indústria & 311 & 3 & 9 & -6 \\
\hline Prestação de serviços & 324 & 2 & 10 & -8 \\
\hline Indústria & 340 & 2 & 10 & -8 \\
\hline Indústria & 364 & 5 & 11 & -6 \\
\hline Indústria & 600 & 20 & 24 & -4 \\
\hline Indústria & 670 & 18 & 26 & -8 \\
\hline Prestação de serviços & 725 & 2 & 29 & -27 \\
\hline Indústria & 800 & 22 & 32 & -10 \\
\hline Indústria & 820 & 54 & 33 & 21 \\
\hline Indústria & 850 & 3 & 34 & -31 \\
\hline Comércio & 914 & 28 & 46 & -18 \\
\hline Prestação de serviços & 935 & 38 & 37 & 1 \\
\hline Indústria & 978 & 57 & 49 & 8 \\
\hline Prestação de serviços & 1010 & 36 & 51 & -15 \\
\hline Prestação de serviços & 1086 & 18 & 54 & -36 \\
\hline Prestação de serviços & 1200 & 12 & 60 & -48 \\
\hline Indústria & 1900 & 23 & 95 & -72 \\
\hline Prestação de serviços & 2000 & 33 & 100 & -67 \\
\hline Indústria & 4800 & 23 & 240 & -217 \\
\hline Indústria & 5200 & 100 & 260 & -160 \\
\hline Prestação de serviços & 23000 & 100 & 1150 & -1050 \\
\hline
\end{tabular}

\section{As eMPresas e a CONTRATAÇão de PNE's}

Quando perguntadas sobre o motivo que as levava à contratação de pessoas com necessidades especiais, a maioria das empresas (cerca de $42 \%$ ) fez alusão à exigência da Lei de Cotas e 31\% delas alegou contratar PNE's em função de sua política de responsabilidade social. As demais empresas responderam que as contratações eram feitas porque os profissionais atendiam as exigências da 
empresa $(18 \%)$ ou porque os dirigentes da empresa tinham consciência da necessidade de inclusão de PNE's no mercado de trabalho (9\%).

Sobre o perfil das PNE's contratadas, foram traçadas as principais exigências ou preferências das empresas para a seleção de candidatos. Observouse que cerca de $43 \%$ das empresas exigiam, no mínimo, Ensino Fundamental completo dos candidatos e 33\% exigiam Ensino Médio (completo ou em curso). Possivelmente em função dessa exigência de escolarização, os tipos de necessidades especiais mais presentes nas empresas foram a deficiência auditiva (40\%), a deficiência física $(40 \%)$ e a deficiência visual $(14 \%)$. Para o recrutamento de candidatos, as empresas, em geral, afirmaram procurar os serviços de agências de emprego (56\%), incluindo, aí, os serviços do SINE, agência de empregos ligada ao Governo Federal. Apenas 15\% das empresas fizeram referência a convênios com instituições educacionais para PNE's. Perguntadas sobre a existência de programas de treinamento ou acompanhamento de PNE's no trabalho, a maioria das empresas (53\%) respondeu possuir esse tipo de programa. As demais não citaram qualquer ação nesse sentido.

Todas as empresas participantes afirmaram ter dificuldades para contratar PNE's. Essas dificuldades são explicitadas na Figura 1. Dentre as mais citadas pelas empresas, três estavam relacionadas ao candidato em si: $30 \%$ das respostas fizeram alusão à sua baixa escolaridade, $16 \%$ à sua qualificação profissional ruim e $6 \%$ fizeram menção a possíveis problemas de conduta. Interessante notar que $25 \%$ das empresas afirmaram existir pouca oferta de mãode-obra no mercado, afirmação que se choca com a taxa de desemprego encontrada entre as pessoas com necessidades especiais.

Figura 1 - porcentagem de respostas das empresas sobre as dificuldades encontradas na contratação de PNE'S.

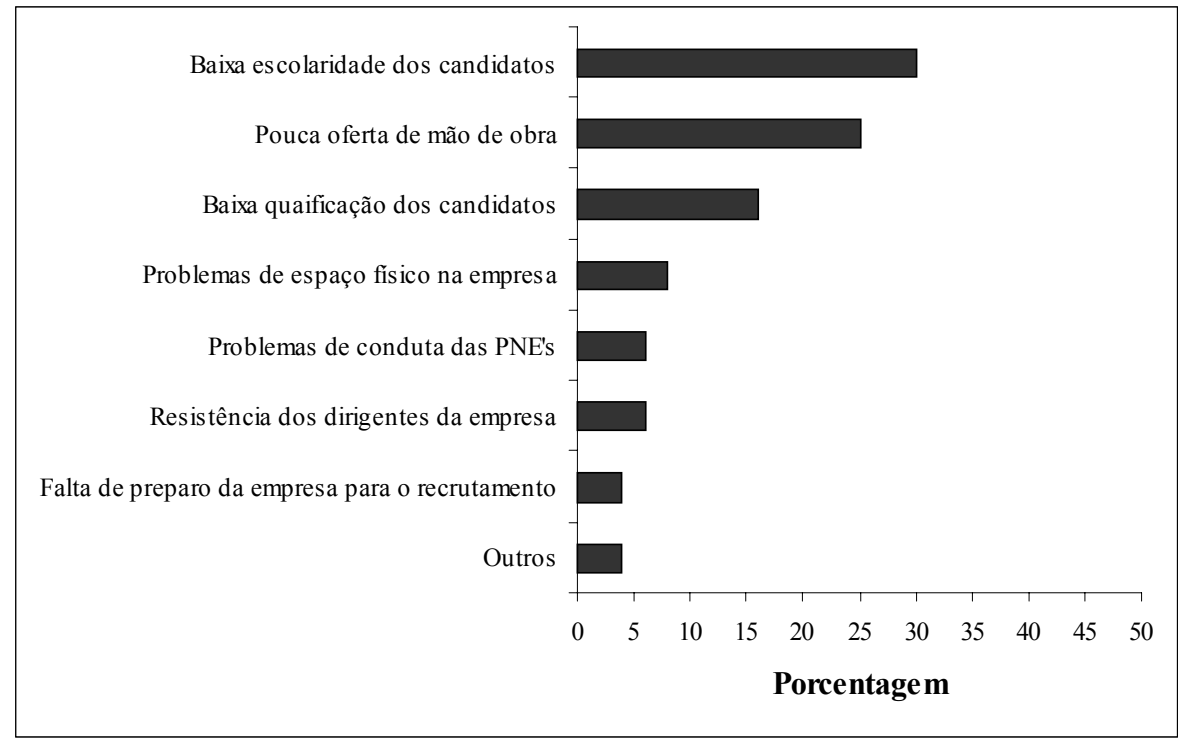




\section{CARACTERIZAÇÃO DAS INSTITUIÇÕES EDUCACIONAIS}

Foram entrevistadas 10 instituições educacionais. O critério de seleção dessas instituições é que elas trabalhassem com adolescentes e adultos com necessidades especiais, tendo sido descartadas outras 13 instituições inicialmente contatadas que não se enquadravam nesse critério. Todas as instituições contatadas (mesmo aquelas que não fizeram parte da amostra) aceitaram colaborar com a pesquisa.

A maioria das instituições (8) era de natureza filantrópica e atendia adolescentes e/ou adultos com necessidades especiais diversas: deficiência mental (4), visual (4), física (3), auditiva (3), múltipla (4) e autismo (3). A Tabela 2 apresenta mais detalhes sobre a caracterização das instituições educacionais participantes.

Tabela 2 - Caracterização das instituições educacionais/ associações participantes da pesquisa.

\begin{tabular}{|c|c|c|c|}
\hline $\begin{array}{l}\text { Natureza da } \\
\text { instituição }\end{array}$ & Tipo de NE atendida & $\begin{array}{l}\text { Faixa etária das } \\
\text { pessoas atendidas }\end{array}$ & $\begin{array}{l}\mathrm{N}^{\circ} \text { de pessoas } \\
\text { atendidas }\end{array}$ \\
\hline Filantrópica & Def. Múltipla & Até 30 anos & 175 alunos \\
\hline Filantrópica* & Def. Visual & Todas as idades & 3000 associados \\
\hline Filantrópica* & Def. Física & Acima de 17 anos & 3500 associados \\
\hline Filantrópica & Todos os tipos & Acima de 18 anos & 110 alunos \\
\hline Particular & Autismo & Acima de 14 anos & 18 alunos \\
\hline Filantrópica & Def. Visual & Todas as idades & 280 alunos \\
\hline Particular & Todos os tipos & Até 18 anos & 50 alunos \\
\hline Filantrópica & Def. Mental e múltipla & Até 27 anos & 58 alunos \\
\hline Filantrópica & Def. Auditiva & Até 22 anos & 89 alunos \\
\hline Filantrópica & Def. Mental & Acima de 14 anos & 428 alunos \\
\hline
\end{tabular}

Nota: As instituições assinaladas com * não são propriamente educacionais; são associações que agregam pessoas com necessidades especiais específicas e prestam serviços aos associados, incluindo cursos de profissionalização.

\section{As INSTITUiÇões edUCACIONAIS E A PREPARAÇÃo/INCLUSÃo de PNE's No MERCADO DE TRABALHO}

Ao serem perguntadas sobre os tipos de atendimento oferecidos aos alunos/associados, as instituições enumeraram uma série de serviços diversos, que podem ser observados na Figura 2. A maioria das instituições $(70 \%)$ relatou oferecer encaminhamento para o trabalho e $50 \%$ delas afirmaram possuir oficinas ou unidades de trabalho supervisionado nas suas dependências. Quanto à escolarização, cinco instituições encaminhavam seus alunos/associados para receber educação formal em instituições educacionais regulares e quatro delas ofereciam esse trabalho em suas dependências. As instituições ainda relataram 
encaminhar alunos/associados para cursos de informática em outras instituições $(40 \%)$ ou oferecer tais cursos em suas próprias dependências $(20 \%)$. Outras atividades relacionadas à profissionalização citadas pelas instituições foram avaliação de perfil vocacional $(20 \%)$ e treinamento para o trabalho e cidadania $(20 \%)$.

Figura 2 - Porcentagem de respostas das instituições escolares sobre os tipos de atendimento oferecidos aos alunos/associados (cada instituição poderia citar mais de um tipo de atendimento).

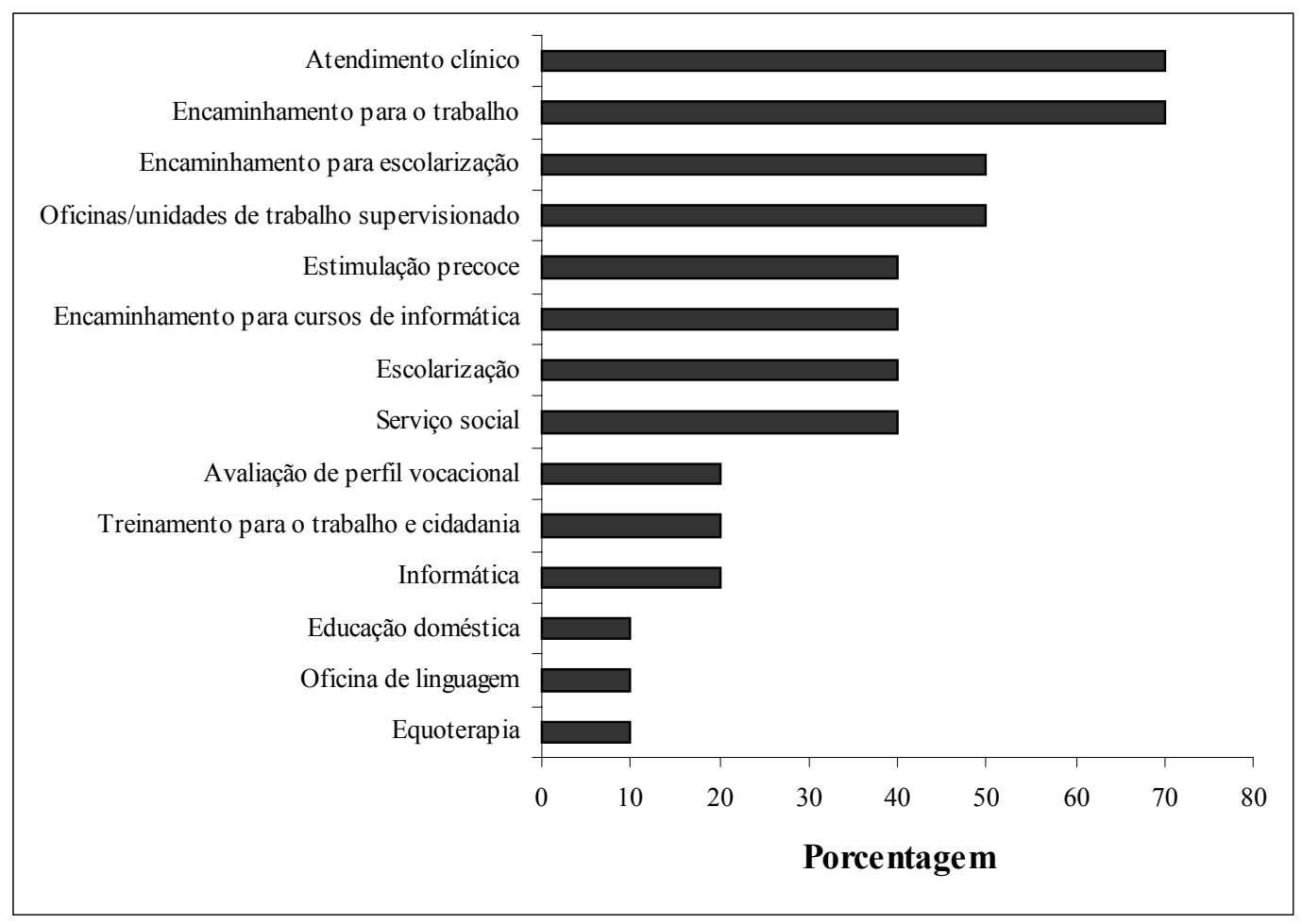

As instituições educacionais mantinham diferentes profissionais envolvidos no processo de formação e encaminhamento profissional de seus alunos/associados. Os mais citados foram professores/instrutores $(70 \%)$, psicólogos e assistentes sociais $(60 \%)$ e pedagogos (50\%). Com menor freqüência foram citados profissionais como terapeutas ocupacionais, fonoaudiólogos, fisioterapeutas e advogados.

Metade das instituições afirmou que o desenvolvimento de habilidades específicas para o trabalho é -um aspecto necessário para a inclusão profissional de PNE's. No entanto, apenas $20 \%$ delas citaram a escolarização e a capacitação profissional (como cursos profissionalizantes, por exemplo) como fatores 
necessários ao processo. Ao serem perguntadas sobre quais aspectos ligados especificamente à profissionalização de PNE's eram trabalhados na instituição, os mais citados foram o desenvolvimento de habilidades específicas (como higiene, por exemplo) e a capacitação profissional (ensino de uma profissão específica), mencionados por $70 \%$ e $50 \%$ das instituições, respectivamente. Apenas 3 instituições responderam proporcionar escolarização para seus alunos/associados e duas delas afirmaram trabalhar a empregabilidade deles.

A maioria das instituições participantes afirmou ter programas de acompanhamento ao aluno/associado quando este consegue um emprego. As práticas de acompanhamento descritas com mais freqüência pelas instituições foram a sensibilização dos funcionários da empresa contratante sobre a deficiência (60\%), o acompanhamento do aluno no próprio local de trabalho por um período inicial de tempo (50\%) e o acompanhamento da família (20\%).

Finalmente, quando se pediu a opinião das instituições sobre os processos adotados pelas empresas para a contratação de PNE's, de modo geral as respostas apontaram aspectos negativos desse processo. Metade das instituições afirmou que falta solidariedade, tolerância ou uma "visão mais humana" por parte das empresas. Três instituições afirmaram que as empresas possuem poucas informações sobre o que são realmente as necessidades especiais, desconhecendo o potencial das pessoas e apenas enfatizando suas dificuldades, e $20 \%$ delas reclamaram que as empresas contratam PNE's apenas por causa da legislação, sem se importar realmente com a inclusão social dessas pessoas.

\section{Discussão e CONCLUSÕES}

De modo geral, os dados apresentados mostram que a grande maioria das empresas entrevistadas não consegue cumprir a Lei de Cotas, ainda que, predominantemente, afirmem que contratam PNE's exatamente por causa da pressão da referida Lei. Para a maioria das empresas o grande empecilho à contratação de PNE's é a escolarização, já que a exigência mínima declarada pelas empresas participantes foi de Ensino Fundamental completo. Sobre isso, é importante considerar que o ingresso no mercado de trabalho é apenas um aspecto da inclusão, talvez o elo final de uma cadeia muito mais complexa. Para que esse processo seja bem sucedido, inúmeras etapas anteriores deveriam ser cumpridas. A Lei de Cotas se apresenta como medida paliativa à atual situação de exclusão social e outras medidas complementares poderiam ser empregadas para pressionar a iniciativa privada a abrir oportunidades de emprego para PNE's (como, por exemplo, a exigência do cumprimento da Lei de Cotas para que as empresas obtivessem a certificação ISO). Porém, novamente tais medidas atingiriam apenas o ponto final de uma cadeia que envolve o compromisso do governo em assegurar direitos básicos às PNE's, como saúde e educação de qualidade, por exemplo. Exatamente por isso, muitos autores criticam a Lei de Cotas. Além de descreverem 
casos de empresas que registram PNE's para que fiquem em casa, apenas com o objetivo de preencher sua cota (o que, por princípio, contraria a finalidade primeira de Lei - dar acesso à PNE ao mercado de trabalho), ou de chamar a atenção para o fato de que a Lei não leva em conta se existem pessoas suficientemente qualificadas para ocupação das cotas (NERI; CARVALHO; COSTILHA, 2002), existem ainda argumentos que alegam ser a Lei de Cotas uma "medida discriminatória às avessas" e não inclusiva (SASSAKI, 1997).

Independente da polêmica sobre a validade ou não de medidas de ação afirmativa desse tipo, é inegável o fato de que existem metas de inclusão anteriores ao acesso ao mercado de trabalho e que não estão sendo cumpridas. Prova disso é o número de instituições especializadas que afirmaram proporcionar escolarização para seus alunos/associados: menos da metade das instituições participantes declarou oferecer esse tipo de serviço, e apenas duas delas declararam que este é um fator importante para que a PNE possa ingressar de forma competitiva no mercado de trabalho. Talvez por considerarem, em sua maioria, que o desenvolvimento de habilidades específicas é mais importante para obtenção de um emprego, esse foi o principal tipo de ação de profissionalização referida pelas instituições. Observa-se, aqui, um problema de difícil solução. Se as empresas têm uma exigência de pelo menos oito anos de escolarização para contratação de funcionários e se as instituições que atendem PNE's não oferecem esse serviço, certamente tal nível de escolarização só poderia ser atingido por aquelas PNE's que freqüentam o ensino regular. Dados do Ministério da Educação mostram, porém, que em 1999, cerca de $10 \%$ das crianças e jovens com necessidades especiais freqüentavam classes comuns do ensino regular, número que aumentou para cerca de $40 \%$ em 2005 (MEC/INEP). Apesar desse aumento, porém, esses dados também mostram que a maioria das crianças e adolescentes com necessidades especiais freqüenta, ainda, modalidades segregadas de ensino, entre elas, as escolas especiais. Além disso, é preciso considerar que a matrícula no ensino regular não garante que tais alunos conseguirão completar o ensino fundamental. Em uma revisão de pesquisas sobre inclusão, Mendes (2004) alerta que "o fracasso escolar poderia afetar com mais intensidade os portadores de deficiências, menos em função de suas dificuldades, do que pelas limitações impostas pelo nosso sistema educacional" (p. 225). As deficiências da educação básica no Brasil são de ordem geral e os dados apresentados pelos relatórios anuais do Ministério da Educação sobre a educação inclusiva no país apontam para uma série de problemas e dificuldades do poder público para oferecer educação formal de indivíduos que apresentem necessidades especiais.

Talvez por depender de iniciativas próprias de escolarização as PNE's preferencialmente contratadas pelas empresas são aquelas com deficiência auditiva, física ou visual. Esse dado parece refletir dois aspectos. Primeiro, tais necessidades especiais são aquelas que acarretam menos dificuldades na escolarização regular, já que existem recursos desenvolvidos e testados para promover a aprendizagem formal desses indivíduos quando necessário. Portanto, é mais fácil para essas pessoas atingir os níveis de escolarização exigidos pelas empresas nos ambientes 
regulares de ensino. Tais necessidades especiais também demandam menos adaptações das próprias empresas no planejamento de ações de capacitação específica para esses funcionários, ou seja, as empresas não parecem precisar investir uma soma alta de dinheiro para contratação de pessoas especializadas para planejar cursos de capacitação ou para ministrar aulas para esses trabalhadores, já que eles apresentam plenas condições de participar de programas dirigidos aos demais funcionários. A pergunta que se impõe, a partir dessas considerações, refere-se àquelas PNE's que apresentam condições que exigem maior investimento em adaptações para sua escolarização e adaptação ao ambiente de trabalho, como é o caso da deficiência mental, da deficiência múltipla e do autismo. Sobre a profissionalização de pessoas com deficiência mental, Cestani (2002) afirma que a inclusão no mercado de trabalho dessa população é uma idéia muito recente e não muito aceita, já que são grandes as barreiras para essas pessoas e poucas as oportunidades de trabalho a elas destinadas. Diante disso, de que forma se pode proporcionar oportunidades também a essas pessoas? Quais as ações que empresas e instituições educacionais devem empreender para permitir que também elas possam ser beneficiadas com medidas inclusivas no mercado de trabalho? Os dados desta pesquisa, infelizmente, não respondem a essas questões, mas certamente elas merecem atenção especial por parte dos pesquisadores da área.

Finalmente, um último dado revela mais um descompasso na relação empresas/ instituições: poucas empresas afirmaram fazer contato direto com escolas ou associações quando da contratação de PNE's, havendo uma clara preferência para agências de emprego convencionais. Por sua vez, apenas duas instituições afirmaram buscar um contato direto com as empresas para colocação de seus alunos/associados em postos de trabalho. Nenhuma das instituições pesquisadas afirmou possuir programas de emprego apoiado (prática recomendada pela literatura especializada na área - RAGAZZI, 2001; ARANHA, 2003), e as ações citadas se restringiram a palestras de sensibilização nas empresas e algum acompanhamento quando o aluno conseguia uma colocação. É importante ressaltar que esse acompanhamento não foi citado como uma prática sistemática que fizesse parte de um processo mais amplo de profissionalização. Diante dessa realidade, apresenta-se um impasse importante. As empresas não buscam o apoio das instituições especializadas para busca de candidatos potenciais para suas vagas e as instituições não oferecem serviços de apoio às contratações que justifiquem um interesse maior por parte das empresas. Possivelmente, a falta de mão-de-obra disponível relatada pelas empresas tenha relação com esse impasse, já que a falta de um contato maior entre as duas partes favorece essa impressão por parte do empresariado.

É importante considerar que os dados aqui apresentados refletem uma realidade que talvez pudesse ser melhor interpretada se se soubesse o significado de profissionalização e colocação no mercado de trabalho do ponto de vista das empresas e das instituições formadoras. Se as empresas admitem funcionários com necessidades especiais em função da pressão exercida pela legislação e se as escolas 
não priorizam a escolarização e capacitação das PNE's para o mercado de trabalho, certamente existem crenças que subjazem a essas práticas. Investigar quais são essas crenças forneceria indícios sobre outros obstáculos à profissionalização e ao ingresso da PNE no mercado de trabalho. O que os dados mostram, porém, é que as instituições especializadas e as empresas ainda encontram muitas dificuldades em estabelecer um diálogo produtivo que favoreça de fato a PNE. Por um lado, empresas apontam para a baixa escolaridade, a falta de qualificação e a insuficiência de PNE's disponíveis e qualificadas para a ocupação dos postos exigidos pela Lei de Cotas; por outro, instituições reclamam da falta de tolerância, solidariedade e paciência das empresas para com a PNE. Nessa dissonância de discursos, talvez seja necessário ouvir as próprias pessoas com necessidades especiais para que elas, as maiores beneficiárias de todo o processo, possam indicar caminhos que ajudem na resolução desse problema (GOYOS et al., 1989).

A pesquisa aqui relatada se apresenta como um retrato pontual da amostra estudada. O pequeno número de participantes impede que se possa fazer generalizações mais amplas sobre seus resultados, mas os dados aqui apresentados apontam para questões relevantes que ainda devem ser abordadas com mais profundidade. Somente com o estudo de tais questões será possível fazer com que a inclusão social das PNE's saia da retórica e se transforme em um conjunto de ações efetivas que beneficiem a sociedade como um todo.

\section{REFERÊNCIAS}

ARANHA, M.L.A. História da educação. São Paulo: Moderna, 2001.

ARANHA, M.S.F. Trabalho e emprego: instrumento de construção da identidade pessoal e social. Brasília: Corde, 2003.

BRASIL. Constituição da República Federativa do Brasil. Brasília (DF): Senado, 1988.

BRASIL. Lei n. 8.213, de 24 de julho de 1991. Dispõe sobre os planos de benefícios da Previdência Social e dá outras providências. Brasília, DF, 1991. Disponível em http:// www010.dataprev.gov.br/sislex/paginas/42/1991/8213.htm. Acesso em: 12 fev. 2006.

DILL, I.L. Os desafios atuais no mundo do trabalho. In: BENTO, M.A.; CASTELAR, M. (Orgs.). A inclusão no trabalho: desafios e perspectivas. São Paulo: Casa do Psicólogo, 2001, p. 105-114.

GOYOS, A.C.N.; MANZINI, E. J.; CARVALHO, M.B.; BALTASAR, M.F.; MIRANDA, T.G. Justificativas para a formação profissional do deficiente mental: revisão da literatura brasileira especializada. Cadernos de Pesquisa, São Paulo, v. 69, p. 53-67, maio 1989.

MARTINS, L.A.R. Inclusão. In: MARQUEZINE, M.C. et al. (Orgs.) Inclusão. Londrina: Eduel, 2003, p. 9-14.

MENDES, E.G. Construindo um "locus" de pesquisas sobre inclusão escolar. In: MENDES, E.G.; ALMEIDA, M.A.; WILLIAMS, L.C.A. (Orgs.) Temas em educação especial: avanços recentes. São Carlos: EdUFSCar, 2004, p. 221-230. 
NERI, M.; CARVALHO, A.P.; COSTILHA, H.G. Políticas de cotas e inclusão trabalhista de pessoas com deficiência. Ensaios Econômicos da EPGE/FGV, Rio de Janeiro, v. 462, 2002. Disponível em: http:/ / www.epge.fgv.br/portal/arquivo/1310.pdf. Acesso em: 12 fev. 2006.

RAGAZZI, C.L.M. Emprego com apoio: alternativa viável para inserção de pessoas com deficiência mental no mercado de trabalho? 2001. Dissertação (Mestrado em Educação Especial - Educação do Indivíduo Especial) - Universidade Federal de São Carlos, São Carlos.

SASSAKI, R.K. Inclusão: construindo uma sociedade para todos. Rio de Janeiro: WVA, 1997.

TANAKA, E.D.O.; RODRIGUES, R.R.J. Em busca de novas expectativas de trabalho para o portador de deficiência mental. In: MARQUEZINE, M.C. et al. (Orgs.) Inclusão. Londrina: Eduel, 2003, p. 323-330.

Recebido em: 18/04/2006

Reformulado em: 30/04/2006

Aceito em: 30/05/2006 